\title{
Phenoxazine derivative, 2-amino-4,4a-dihydro-4a,7-dimethyl- 3H-phenoxazine-3-one suppresses growth of human retinoblastoma cell line Y79 in vitro and in vivo
}

\author{
KEISUKE KIMURA $^{1}$, YOSHIHIKO USUI ${ }^{1}$, TAKAAKI HATTORI ${ }^{1}$, NAOHIKO YAMAKAWA ${ }^{1}$, HIROSHI GOTO ${ }^{1}$, \\ MASAHIKO USUI $^{1}$, SHINYA OKADA ${ }^{2}$, KEN SHIRATO $^{3}$ and AKIO TOMODA ${ }^{4}$ \\ ${ }^{1}$ Department of Ophthalmology, Tokyo Medical University, Nishi-Shinjuku 6-7-1, Tokyo 160-0023; ${ }^{2}$ Department of \\ Pathology, Tokyo Medical University, Shinjuku 6-1-1, Tokyo 160-0020; ${ }^{3}$ Laboratory of Physiological Sciences, Faculty of \\ Human Sciences, Waseda University, Mikajima 22-579-15, Tokorozawa 359-1192; ${ }^{4}$ Department of Biochemistry and \\ Intractable Immune Disease Research Center, Tokyo Medical University, Shinjuku 6-1-1, Tokyo 160-0020, Japan
}

Received June 14, 2007; Accepted September 11, 2007

\begin{abstract}
The aim of the study was to evaluate the in vitro and in vivo antitumor effects of the 2-amino-4,4 $\alpha$-dihydro$4 \alpha, 7$-dimethyl-3H-phenoxazine-3-one (Phx-1) on the human retinoblastoma cell line Y79. The in vitro effects of Phx-1 on cell viability and apoptosis of the human retinoblastoma Y79 cells, were studied by using colorimetric and flow-cytometric methods. The in vivo antitumor effects of Phx-1 on the human retinoblastoma Y79 cells subcutaneously transplanted in $\mathrm{BALB} / \mathrm{c}$ nude mice were studied, examining the tumor size, the adverse effects on the mice and the histopathological evaluations including hematoxylin and eosin and immunohistochemical staining in the mass of tumors of human retinoblastoma Y79 cells isolated from the mice. Phx-1 suppressed the viability of Y79 cells dose- and timedependently and induced apoptosis in Y79 cells in vitro. Phx-1 markedly reduced the growth of Y79 cells transplanted into the mice without causing bodyweight loss. Pathological findings of the tumor mass isolated from mice revealed that the tumor of Y79 cells treated with Phx-1 had a decreased mitotic index, decreased expression of Ki67 and p53, no alteration of bcl-2 level and increased caspase-3 activity compared with the the control. Present results suggested that Phx-1 demonstrated antitumor activity against the human retinoblastoma Y79 cells in vitro and in vivo, by inhibiting cell growth and inducing apoptosis. In addition, Phx-1 exerted few adverse side effects on the mice. Phx-1 may be a useful
\end{abstract}

Correspondence to: Dr Akio Tomoda, Department of Biochemistry and Intractable Immune Disease Research Center, Tokyo Medical University, Shinjuku 6-1-1, Tokyo 160-0020, Japan E-mail: tomoda@tokyo-med.ac.jp

Key words: phenoxazine, human retinoblastoma cells, growth inhibition antitumor drug in the treatment of retinoblastoma, which is the most common and serious intraocular malignant tumor.

\section{Introduction}

Retinoblastoma is a malignant intraocular tumor occurring mainly in infants and children (1-4). Due to the advances in conservative methods such as external beam radiotherapy and chemoreduction therapy against this malignancy, patient outcome has improved greatly (3). However, irradiation causes a secondary generation of malignant tumors and cosmetic problems (4) and some antitumor drugs cause adverse side effects, e.g, etoposide and teniposide are shown to induce the secondary generation of malignant tumors $(4,5)$. Although systematic chemotherapy using a three-drug regimen consisting of vincristine, etoposide and carboplatin was recently adopted for the treatment of retinoblastoma (4), novel chemotherapeutic agents need to be developed to treat retinoblastoma with few adverse effects.

Tomoda et al found that a novel phenoxazine derivative, 2-amino-4,4 $\alpha$-dihydro-4 $\alpha, 7$-dimethyl-3H-phenoxazine-3-one (Phx-1), which is a type of phenoxazine and is soluble in water after dissolution in ethanol or dimethylsulfoxide, could be synthesized by the reaction of 2-amino-5-methylphenol with human or bovine hemoglobin $(6,7)$. Since phenoxazine is an essential component of actinomycin D (8), it is possible that phenoxazine derivatives may exert some antitumor activity. It was demonstrated that $\mathrm{Phx}-1$ suppresses the proliferation of cancer cell lines such as human epidermoid carcinoma cells, human adenocarcinoma cells and human leukemia cells in vitro and in vivo with few adverse side effects (9-11). These findings prompted us to investigate whether $\mathrm{Phx}-1$ may inhibit the proliferation of retinoblastoma in vitro and in vivo.

In this study, we investigated the effect of Phx-1 on the proliferation and apoptosis of the retinoblastoma cell line Y79 that is often used for the basal cancer research of retinoblastoma. We also studied the antitumor effects of Phx-1 on Y79 cells transplanted into nude mice, investigating the reduction of tumor size and examining pathological and 


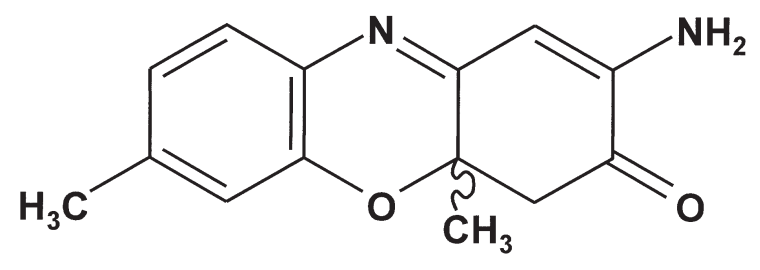

Figure 1. Chemical structure of 2-amino-4,4 $\alpha$-dihydro-4 $\alpha, 7$-dimethyl-3Hphenoxazine-3-one (Phx-1).

immunohistochemical findings in the mass of Y79 cell tumors in the backs of nude mice.

\section{Materials and methods}

Compounds. Phx-1 was synthesized and purified as described previously (11), dissolved in ethanol before use and then diluted with RPMI-1640 medium to appropriate concentrations. The chemical structure of Phx-1 is shown in Fig. 1.

Cell lines. The human retinoblastoma cell line, Y79, was kindly provided by Dr Akihiro Kaneko from the Division of Ophthalmology, National Cancer Institute, Tokyo, Japan.

Animals. BALB/c nu/nu female mice, 5 weeks old, were kept in special pathogen-free conditions at room temperature and $55 \%$ humidity with a circadian light rhythm of $12 \mathrm{~h}$ and were given CLEA Rodent Diet (CA-1) and tap water. The present study was carried out according to the 'ARVO Statement for the Use of Animals in Ophthalmic and Vision Research'.

Cell culture. Cells were cultured in RPMI-1640 medium supplemented with $10 \%$ fetal bovine serum (FBS), glutamine, $100 \mathrm{U} / \mathrm{ml}$ of penicillin and $100 \mu \mathrm{g} / \mathrm{ml}$ of streptomycin in a humidified $95 \%$ air $/ 5 \% \mathrm{CO}_{2}$ atmosphere at $37^{\circ} \mathrm{C}$.

Cell proliferation assay. Cell proliferation was assessed by the Cell Titer-Blue ${ }^{\mathrm{TM}}$ cell viability assay (Promega, WI, USA) method according to the protocol recommended by the manufacturer. Briefly, Y-79 cells $\left(8 \times 10^{4} / \mathrm{ml}\right)$ were suspended in a medium containing 0-100 $\mu \mathrm{M} \mathrm{Phx}-1$. After $24-72 \mathrm{~h}, 1 \mathrm{ml}$ of the suspended cells was added to each well of a 224-well assay plate. The plate was incubated for $1 \mathrm{~h}$. After shaking the plate for $10 \mathrm{sec}$, fluorescence was recorded using a multidetection microplate reader (Powerscan HT, Dainippon Pharmaceutical, Osaka, Japan) at $560 \mathrm{~nm}$ excitation/590 nm emission. Cell viability was determined by referring to the fluorescence of Phx-1-free cells.

Detection of apoptosis. The detection of apoptosis was performed flow cytometrically using the ApoDIRECT in situ DNA fragmentation assay kit [Medical and Biological Laboratories (MBL), Nagoya, Japan], which was based on the terminal deoxy-nucleotidyl transferase (TdT)-mediated deoxyuridine triphosphate (dUTP)-biotin nick end labeling (TUNEL) assay. Briefly, after Y79 cells were incubated with or without Phx-1 for 2 days, the cells were collected, fixed by $1 \%$ (weight/volume) paraformaldehyde in phosphatebuffered saline (PBS) (pH 7.4) and placed on ice for $15 \mathrm{~min}$.
After washing twice with PBS ( $\mathrm{pH} 7.4)$, the cells were fixed by $70 \%$ (volume/volume) EtOH and placed on ice for $30 \mathrm{~min}$. The cells were washed twice with $1 \mathrm{ml}$ of the wash buffer and stained with $50 \mu 1$ of the staining solution containing TdT reaction buffer $(10 \mu 1)$, TdT enzyme $(0.75 \mu 1)$, fluorescein isothiocyanate (FITC)-dUTP $(8 \mu 1)$ and ultrapure water (32.25 $\mu \mathrm{l})$ and incubated at $37^{\circ} \mathrm{C}$ for $1 \mathrm{~h}$. Then, the cells were rinsed twice with $1 \mathrm{ml}$ of the rinse buffer and stained with $500 \mu 1$ of the propidium iodide (PI)/RNase A solution and incubated at room temperature for $30 \mathrm{~min}$ in the dark. These samples were analyzed with a flow cytometer (Partec PAS, Partec). FITC and PI staining were monitored using an FITC signal detector (FL1, $520 \mathrm{~nm}$ ) and phycoerythrin emission signal detector (FL3, 590-650 nm), respectively.

Antitumor effects of Phx-1 in vivo. The human retinoblastoma cell line Y79 was cultured and suspended in Iscove culture medium (Biological Industries, Kibbutz Beit Haemek, Israel) with FBS. Each control or Phx-1-treated group included five mice bearing Y79 retinoblastoma cells. Five mice in the experimental group received $1 \times 10^{7} \mathrm{Y} 79$ retinoblastoma cells in $0.5 \mathrm{ml}$ of a $1: 1$ mixture of matrigel basement membrane matrix (BD Bioscience, MA, USA) and an Iscove culture medium supplemented with $20 \%$ FBS, subcutaneously (s.c.). Then, the tumor volume was recorded every day until the end of the treatment. The tumor volume (TV) was calculated for each individual mouse from the recorded caliper measurements of the longest (L) and shortest (W) dimension, according to the following formula: TV $\left(\mathrm{mm}^{3}\right)=4 / 3 \times \pi \times \mathrm{L} / 2 \times(\mathrm{W} / 2)^{2}$, described by Miyano-Kurosaki et al (12). Once a tumor mass became visible, drug treatment started. Phx-1 was injected s.c. every day for 35 days. A single preparation was used for Phx-1 as $0.5 \mathrm{mg} / \mathrm{ml}$ after dissolving with $10.7 \%$ ethanol. Then, $100 \mu 1$ of this solution was administered into the back of the mouse, to reveal final concentrations of $5 \mathrm{mg} / \mathrm{kg} /$ day, respectively, whereas 5 control mice were injected with the $10.7 \%$ ethanol in normal saline alone $(100 \mu \mathrm{l})$.

Toxicity of Phx-1 to mice. Ten mice transplanted with Y79 cells were classified into two groups, i.e., 5 mice receiving $5 \mathrm{mg} / \mathrm{kg} \mathrm{Phx}-1$ and 5 mice receiving vehicle alone, into the back, daily for 35 days. The bodyweight of these mice was examined daily for 35 days. In order to study the high-dose effects of Phx-1, $40 \mathrm{mg} / \mathrm{kg} \mathrm{Phx}-1$ (Phx-1 as suspension in ethanol solution) was administered intraperitoneally to the mice without the transplantation of Y79 cells, 5 days/week, for 4 weeks. The bodyweight of these mice was also examined for 28 days.

Pathological and immunohistochemical evaluation in mice. After 21 days, a mouse from the control group and a mouse from the experimental group were sacrificed. Then, the tumor mass including the Y79 cells was isolated from these mice by incision, fixed with formalin and embedded in paraffin. The specimens were stained with hematoxylin and eosin (H\&E) to evaluate the pathological features and mitotic figures of the specimens, or were subjected to immunohistochemical staining for Ki67, p53, bcl-2 and caspase-3. Immunohistochemically stained $4-\mu \mathrm{m}$ sections were dewaxed and dehydrated according to routine procedures. Antigen target retrieval was treated by 


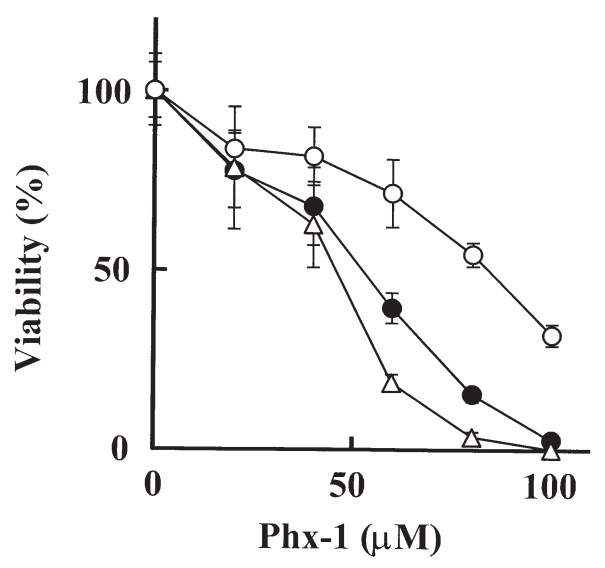

Figure 2. Viability of human retinoblastoma Y-79 cells in the presence or absence of Phx-1. Y-79 cells were cultured for $72 \mathrm{~h}$ at $37^{\circ} \mathrm{C}$ in RPMI-1640 medium with $10 \%$ FBS in the absence (vehicle alone) or presence of various concentrations of $\mathrm{Phx}-1$, as indicated in the figure. Viability was defined as the ratio of cell counts of the samples with $0,20,40,80$ and $100 \mu \mathrm{M} \mathrm{Phx}-1$ to the sample without Phx-1 ( $=4)$. The data represent the mean \pm SD. ( $\bigcirc) 24$; (•) $48 \mathrm{~h}$ and $(\triangle) 72 \mathrm{~h}$.

heating the sections in a microwave oven at $600 \mathrm{~W}$ for $20 \mathrm{~min}$ in citrate buffer ( $\mathrm{pH}$ 6.0). The activity of endogenous peroxidase was blocked with $0.3 \%$ hydrogen peroxide solution containing methanol for $20 \mathrm{~min}$. Then, the sections were incubated all night in a humid chamber at room temperature $\left(20-25^{\circ} \mathrm{C}\right)$ with primary monoclonal antibodies, including antiKi67 (clone MIB-1, dilution 1:400; Dako), anti-p53 (clone DO7, dilution 1:400; Dako), anti-bcl-2 (clone 124, dilution 1:50; Dako) and anti-caspase-3 (clone asp175, dilution 1:2000; Cell Signaling), respectively. The p53 antibody reacted with the wild- and mutant-types of the $\mathrm{p} 53$ protein. The caspase- 3 antibody detected large fragments of activated caspase-3, but did not recognize full length caspase-3 or other cleaved caspases. We used the LSAB2 kit/ HRP (Dako) for immunostaining. Biotin-labeled secondary antibodies (goat anti-rabbit and goat anti-mouse immunoglobulins) (biotinylated link) and streptavidin conjugated to horseradish peroxidase (streptavidin-HRP) were treated by the routine procedure in a humid chamber at room temperature $\left(20-25^{\circ} \mathrm{C}\right)$. The color was developed using 3,3'-diaminobenzidine (DAB) solution. The sections were counterstained with Meyer's hematoxylin. Moreover, we defined the indices as follows for histopathological evaluation. In the H\&E section, 10 microscopic fields in each specimen were examined to evaluate the rate of the mitotic figures (mitotic index, MI), which was defined as the number of metaphase cells/10 high power fields (HPF) (x40). In the immunohistochemical sections, the cells which showed clear nuclear and brown cytoplasmic staining at 10 HPF, were counted as positive.

Statistical analysis. Comparisons between the experimental group and control group were made using the Student's t-test. Values of $\mathrm{p}<0.05$ were considered significant.

\section{Results}

Inhibitory effect of Phx-1 on the proliferation of human retinoblastoma $Y 79$ cells in vitro. Fig. 2 shows the viability of

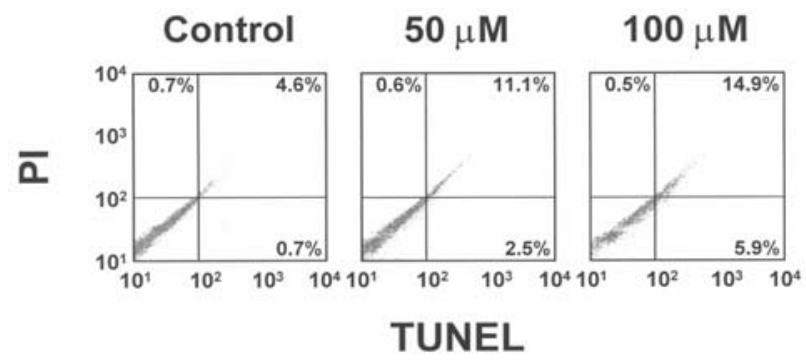

Figure 3. Analysis of the population of cells with early stage apoptosis and the cells with late stage apoptosis/necrosis detected by TUNEL assay. Detection of apoptosis in human retinoblastoma Y-79 cells treated with or without phenoxazines. Y-79 cells were grown in the presence or absence of various concentrations $(0,50$ and $100 \mu \mathrm{M}) \mathrm{Phx}-1$, for $48 \mathrm{~h}$. The apoptosis was detected flow cytometrically by TUNEL assay. In each dot plot, the percentages of TUNEL (-) and PI (-) (viable cells, bottom-left quadrant), TUNEL (+) and PI (-) (cells in early stage apoptosis, bottom-right quadrant), TUNEL (+) and PI (+) (cells in late stage apoptosis/necrosis, top-right quadrant) and TUNEL $(-)$ and PI (+) (cells in necrosis, top-left quadrant) are described.

the human retinoblastoma Y79 cell line treated with different concentrations of Phx-1 for $72 \mathrm{~h}$. According to the increase of the Phx-1 concentration, the growth of the cells was inhibited. The extent of growth inhibition was 25, 40, 80, 98 and $100 \%$, compared with the control with vehicle alone, $72 \mathrm{~h}$ after the addition of 20,40,60,80 and $100 \mu \mathrm{M}$ Phx-1, respectively. These results indicate that $\mathrm{Phx}-1$ inhibits the proliferation of Y79 cells in vitro.

Induction of apoptosis in Y79 cells by Phx-1. Since Phx-1 suppressed the proliferation of Y79 in a dose- and timedependent manner (Fig. 2), we studied the population of apoptotic and necrotic cells in Y79 cells treated with Phx-1 for $48 \mathrm{~h}$, by using a flow-cytometric method (Fig. 3). In this case, double staining of the cells with TUNEL and PI was examined. The described test discriminates intact cells [TUNEL(-)/PI(-)], early apoptotic cells [TUNEL(+)/PI(-)] and late apoptotic/ necrotic cells [TUNEL(+)/PI(+)]. In Fig. 3, non-treated Y79 cells were mainly seen in the control as the bottom-left population of cells which excluded PI and did not bind with TUNEL. In Y79 cells treated with 50 and $100 \mu \mathrm{M}$ Phx-1, TUNEL(+)/PI(-) cells (apoptotic cells, early apoptotic stage; bottom-right quadrant) increased from 0.7 to 2.5 and $5.9 \%$, respectively and TUNEL(+) and PI(+) cells (apoptotic/ necrotic cells, late apoptotic stage; top-right quadrant) increased from 4.6 to 11.1 and $14.9 \%$, respectively. These results suggest that Phx-1 caused the cell death, inducing apoptosis and further apoptosis/necrosis in the human retinoblastoma Y79 cells.

Antitumor effect of Phx-1 on human retinoblastoma Y79 cells transplanted into nude mice. We studied the in vivo antitumor effects of Phx-1 on Y79 cells transplanted into nude mice. The appearance of the mice 35 days after treatment with or without Phx-1 is shown in Fig. 4. In the control mice without treatment of Phx-1 (Fig. 4A), massive white tumors with hemorrhage were present on their backs, where Y79 cells were implanted. An extensive reduction in the tumor size was observed in the mice treated with $5 \mathrm{mg} / \mathrm{kg} /$ day Phx-1 (Fig. 4B).

Fig. 5A-C summarizes the growth of human retinoblastoma Y79 cells transplanted into nude mice, with or without $\mathrm{Phx}-1$ 
A

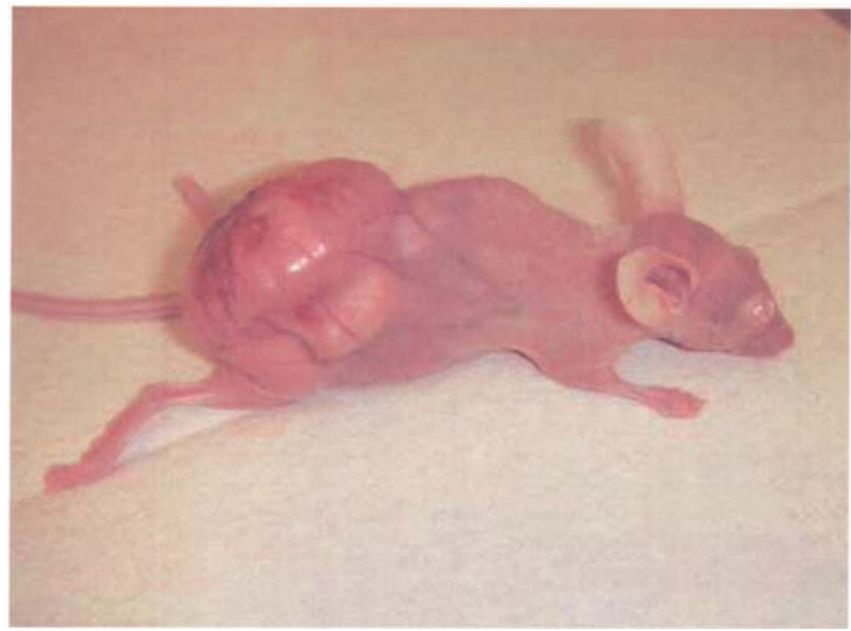

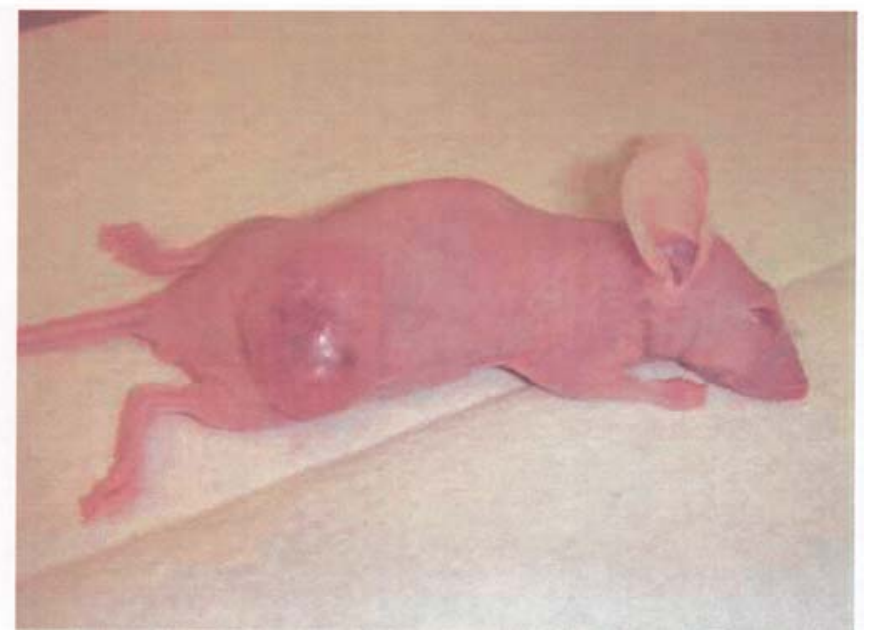

Figure 4. Macroscopic appearance of the mice 35 days after transplantation of the human retinoblastoma cell line Y79, without Phx-1 (A) and with $5.0 \mathrm{mg} / \mathrm{kg}$ Phx-1 (B).

A

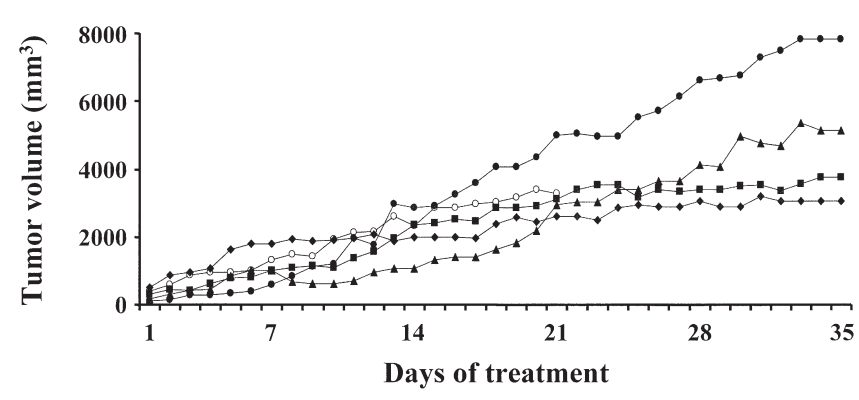

B

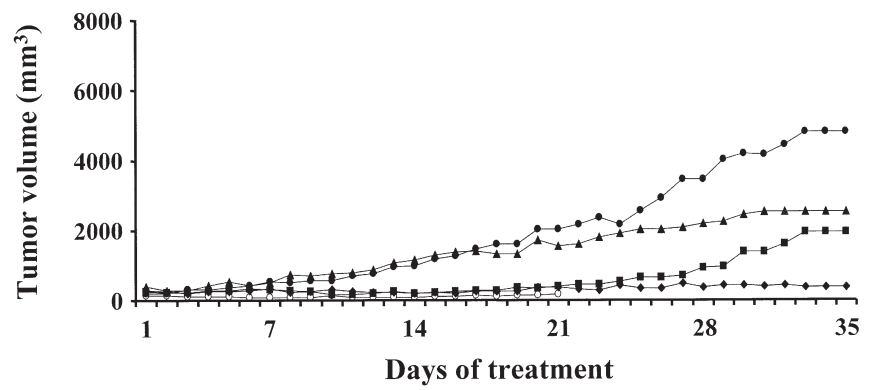

during a 35-day treatment period. During this period, Y79 cells grew rapidly in the control mice (Fig. 5A), while the tumor size was extensively reduced in the mice when treated daily with $5 \mathrm{mg} / \mathrm{kg} /$ day Phx-1 (Fig. 5B). These results are depicted together in Fig. 5C for comparison. The present results indicated that Phx-1 has strong antitumor effects against the human retinoblastoma Y79 cells transplanted into the nude mice. The dose $(5 \mathrm{mg} / \mathrm{kg} /$ day $)$ that was administered in the present experiment is comparable to that used for other strong antitumor drugs such as 5-fluorouracil (5-FU). Daily
C

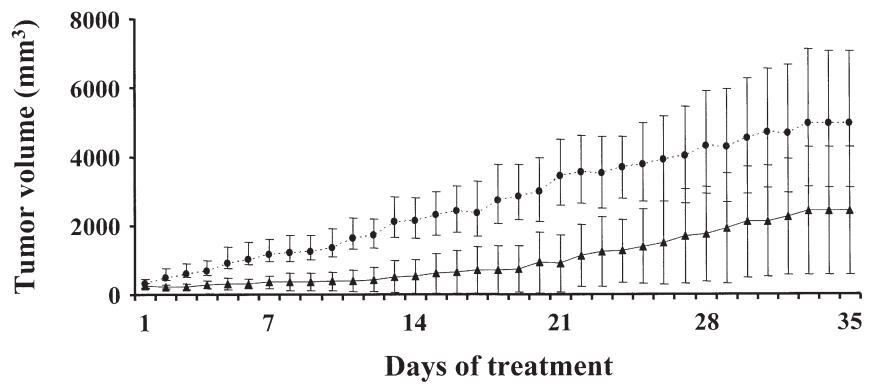

Figure 5. Effect of Phx-1 on tumor growth of Y79 cells transplanted into nude mice. Tumor volume $\left(\mathrm{mm}^{3}\right)$ of 10 mice transplanted with Y79 cells was measured for 35 days, with or without administration of $5 \mathrm{mg} / \mathrm{kg} / \mathrm{day} \mathrm{Phx}-1$, mean \pm SD. (A) Five tumor-bearing mice were treated with normal saline including $10.7 \%$ ethanol. The mouse $(\odot)$ was sacrificed after 21 days of treatment for histopathological examination. (B) Five tumor-bearing mice were treated with $5 \mathrm{mg} / \mathrm{kg} / \mathrm{day} \mathrm{Phx}-1$. The mice with extensively reduced tumors $(\odot)$ were sacrificed after 21 days of treatment for histopathogical examination. (C) Tumor-bearing mice were treated daily with either $5 \mathrm{mg}$ / kg/day Phx-1 (ム) or normal saline (including 10.7\% ethanol) (•).

administration, i.p., of $15.6 \mathrm{mg} / \mathrm{kg} 5$-FU caused $\sim 75 \%$ reduction in the tumor size of Meth A tumor cells transplanted into BALB/c mice, during 14 days (9). However, a marked decrease in bodyweight was indicated in this case (9).

Toxicity of Phx-1 to mice. Since many drugs used for the treatment of cancers are shown to exert various adverse side effects including loss of bodyweight, psilosis and bone marrow suppression, we evaluated the possible toxicity of $5 \mathrm{mg} / \mathrm{kg} /$ day Phx-1, by measuring the changes in bodyweight (Fig. 6). 


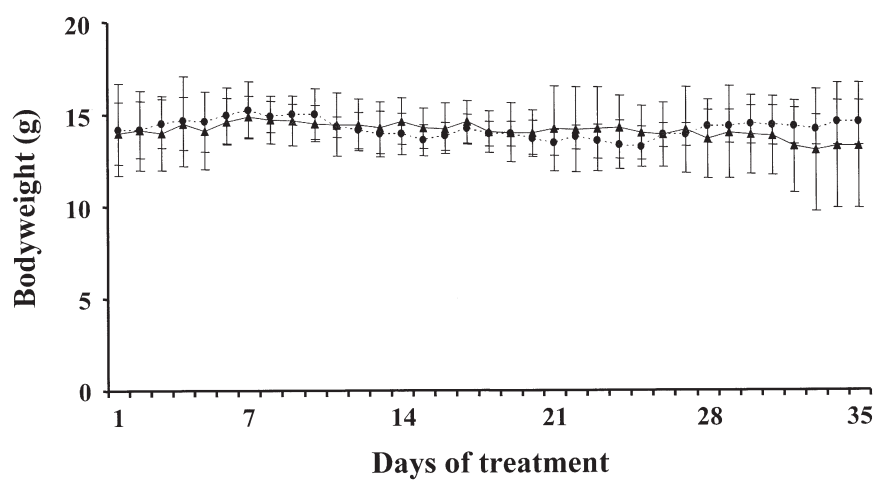

Figure 6. Effects of Phx-1 on bodyweight of mice transplanted with Y79 cells. Bodyweight of 5 mice transplanted with Y79 cells with or without 5 mg/kg Phx-1 was pursued for 35 days. (•) Control treated with $10.7 \%$ ethanol and (^) $5 \mathrm{mg} / \mathrm{kg} \mathrm{Phx}-1$. The data represent the mean \pm SD.

A

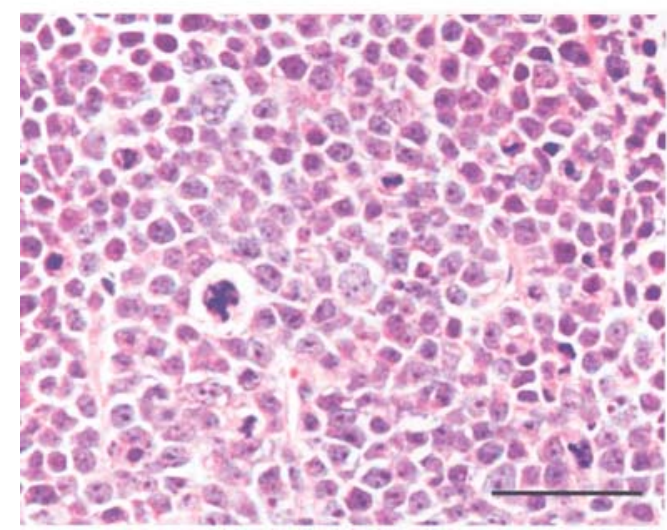

C

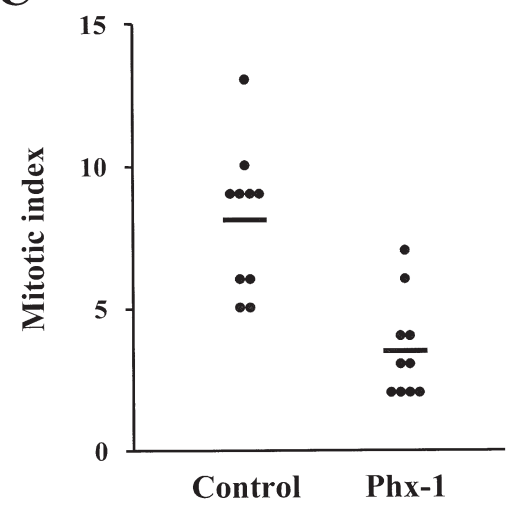

No significant loss of bodyweight was observed in the nude mice treated with $\mathrm{Phx}-1$ for 35 days and no mice died during the observation period, suggesting that $\mathrm{Phx}-1$ may have less adverse effects on mice. Though not shown in the figure, we observed that when $40 \mathrm{mg} / \mathrm{kg} /$ day Phx-1 was administered to the mice without the transplantation of Y79 cells, the bodyweight did not change in these mice for 28 days and no mice died, showing that $\mathrm{Phx}-1$ does not have severe adverse effects on mice at higher doses.

Pathological and immunohistochemical evaluation of Y79 tumor in mice. The pathological features of a mass of tumor transplanted into nude mice, 21 days after the administration of Phx-1 are shown in Fig. 7. In a specimen obtained from a

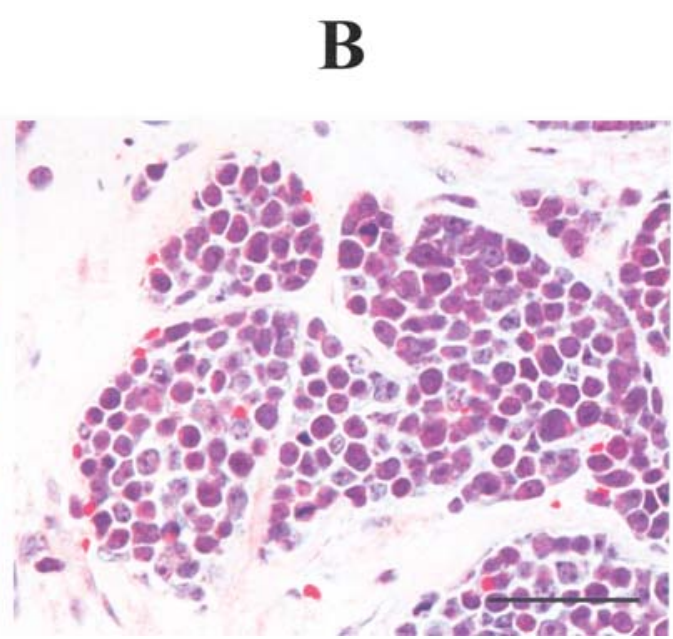

Figure 7. Microscopic features of the tumor mass isolated from mice transplanted with Y79 cells and treated with or without Phx-1 for 21 days. (A) Specimen from a control mouse without administration of $\mathrm{Phx}-1$; (B) specimen from a mouse administered with $5 \mathrm{mg} / \mathrm{kg}$ Phx-1. Bar, $50 \mu \mathrm{m}$. (C) Comparison of mitotic index between the control specimen and the experimental specimen with $\mathrm{Phx}-1$. The number of tumor cells in the metaphase varied in a control mouse from 5 to 13 (mean 8.1), but was significantly lower than that in a Phx-1-treated mouse (range 2-7, mean 3.5). $\mathrm{p}<0.05$; bar in the figure is the mean value.

control mouse with no Phx-1 treatment (Fig. 7A), tumor cells with large and irregular nuclei, in which mitotic figures were often seen and chromatin was gross and granular, proliferated diffusely and at a high density.

On the other hand, in a specimen obtained from an experimental mouse with $5 \mathrm{mg} / \mathrm{kg} /$ day Phx-1 treatment, tumor cells grew with abundant connective tissue (Fig. 7B). degenerated cells with an unclear nuclear structure which were densely stained with H\&E, were markedly increased. These cells were smaller in size, lower in density and had fewer mitotic figures compared with the tumor of the control mouse. These results supported the views that Phx-1 may suppress the proliferation of Y79 cells from a histopathological viewpoint. The rate of mitotic figures, i.e., mitotic index (MI) was 8.1 \pm 2.6 


\section{Control}

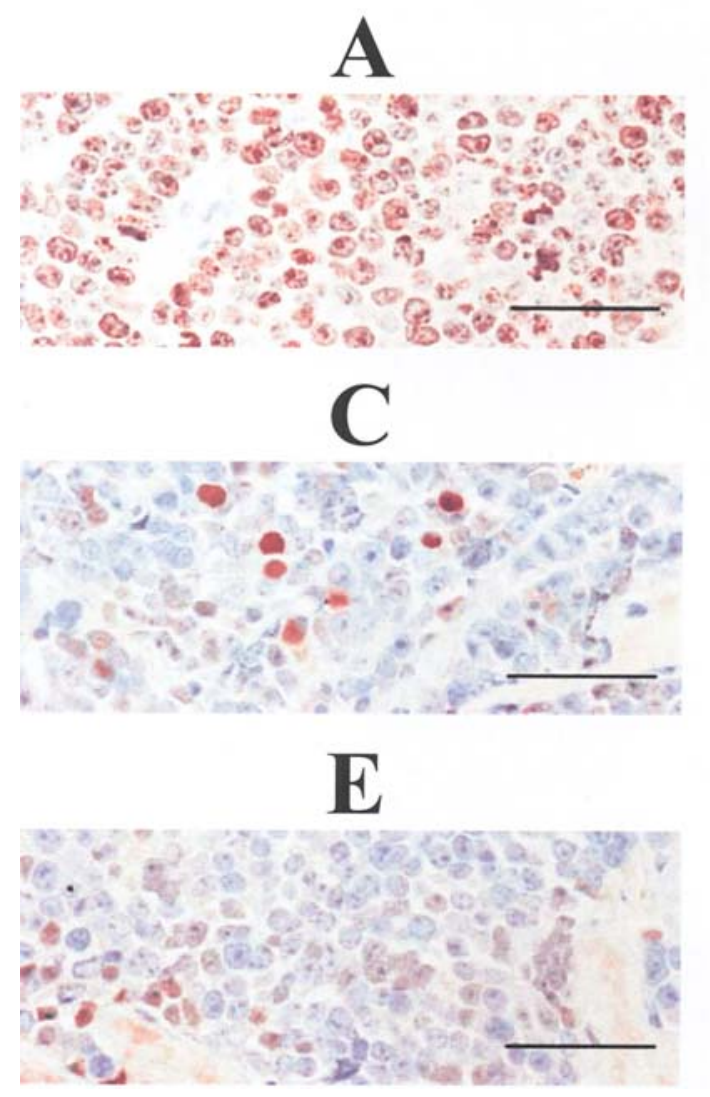

\section{Phx-1}
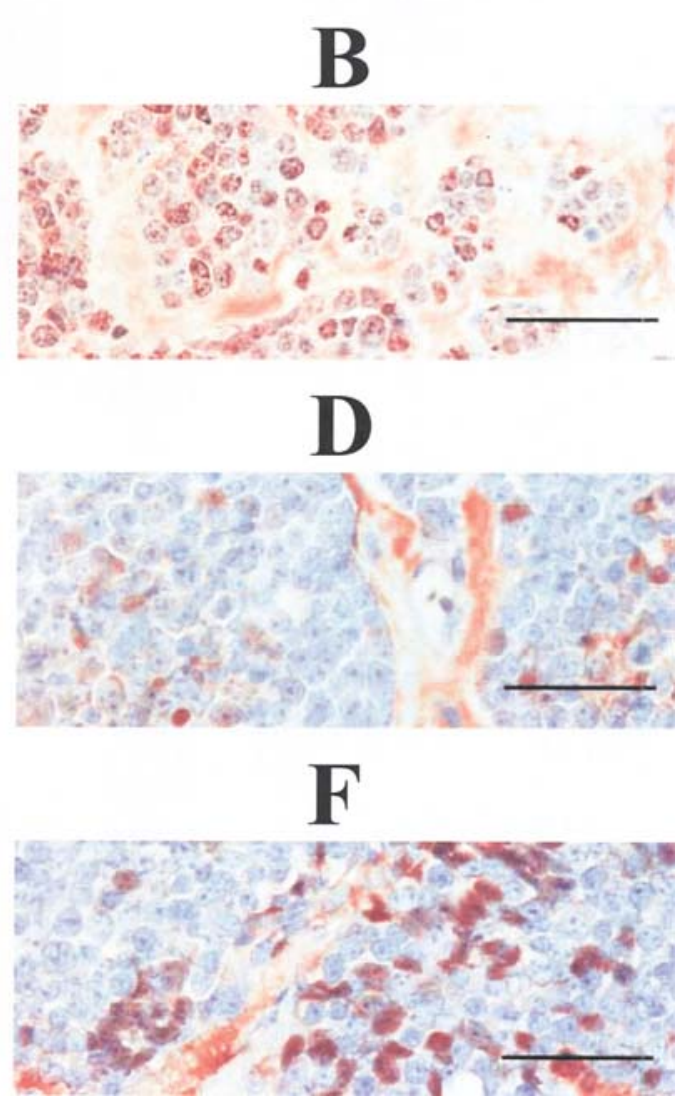

Figure 8. Immunohistochemical staining for Ki67, p53 and caspase-3 of a mass of tumor of Y79 cells isolated from mice without Phx-1 (A, C and E) and with Phx-1 (B, D and F). The tumor cells of (A) show more immunoreactive for Ki67 than those of (B). The tumor cells of (C) show more immunoreactive for p53 than those of (D). The tumor cells of (F) show more immunoreactive for caspase-3 than those of (E). Bar, $50 \mu \mathrm{m}$.

(expressed as the mean $\pm \mathrm{SD}$ ) in the control mouse, while it was $3.5 \pm 1.8$ (the mean $\pm \mathrm{SD}$ ) in a Phx-1-treated mouse, showing that $\mathrm{Phx}-1$ prevented the mitosis of $\mathrm{Y} 79$ cells transplanted in mice (Fig. 7C) $(\mathrm{p}<0.05)$.

Furthermore, we examined the expression of Ki67, p53, bcl-2 and caspase-3 in a tumor mass of Y79 cells transplanted into nude mice, using immunohistochemical staining (positive cells were stained brown). Fig. 8 shows the staining of Ki67 (A and B), p53 (C and D) and caspase-3 (E and F) in the tissues, which were isolated from a mass of tumor, 21 days after the transplantation of Y79 into nude mice with or without treatment of $5 \mathrm{mg} / \mathrm{kg} /$ day $\mathrm{Phx}-1$. Since Ki67 has been recognized as a good marker to evaluate the proliferation ability of cancer cells (13), we examined the number of Ki67 positive cells (designated as the Ki67 reactivity index) in tumor cells at $10 \mathrm{HPF}$ selected from both a control without Phx-1 and an experimental mouse with Phx-1. The Ki67 reactivity index was $44.8 \pm 4.8$ (the mean $\pm \mathrm{SD}$ ) in a control mouse without Phx-1 (Figs. 8A and 9A), while it was 28.6 \pm 9.7 (the mean $\pm \mathrm{SD}$ ) in an experimental mouse with $\mathrm{Phx}-1$ (Figs. 8B and 9A), showing that the proliferation ability of the cells in an experimental mouse treated with $5 \mathrm{mg} / \mathrm{kg} /$ day Phx-1 was much reduced compared with the control mouse.

The levels of p53, bcl-2 and caspase- 3 are shown to be associated with the apoptosis mechanism in cancer cells
(14-16). Thus, we investigated the expression of these proteins in a mass of tumor of Y79 cells transplanted into nude mice. The p53 expression in the tumor of Y79 cells treated with Phx-1 was significantly decreased compared with that in the control without Phx-1 (Figs. 8C, D and 9B). However, no significant differences in the expression of bcl-2 were seen in both the experimental and control mice (Fig. 9C). The expression of caspase- 3 in the experimental mouse (Figs. 8F and 9D) significantly increased compared with that in the control mouse (Figs. 8E and 9D). Thus, the caspase-3 reactivity index was $12.0 \pm 5.6$ (the mean $\pm \mathrm{SD}$ ) in the control mouse without Phx-1, while it was $26 \pm 12.5$ (the mean $\pm \mathrm{SD}$ ) in the experimental mouse with Phx-1. These results suggest that the apoptogenic potential increased in the Y79 cells transplanted into nude mice, 21 days after treatment with $\mathrm{Phx}-1$.

\section{Discussion}

In the present study, we examined the inhibitory effects of Phx-1, which was produced by the reaction of 2-amino-5methylphenol with bovine hemoglobin (7), on the growth of human retinoblastoma Y79 cells in vitro and in vivo. In vitro, Phx-1 prevented the proliferation of the cells, dose- and timedependently (Fig. 2). These results were consistent with previous reports on the antitumor effects of $\mathrm{Phx}-1$ on various 
A

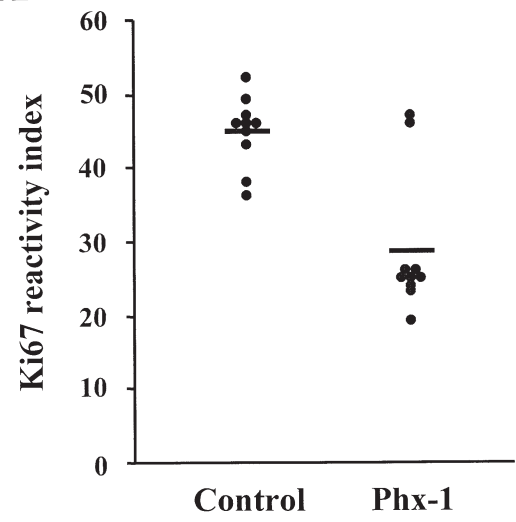

C

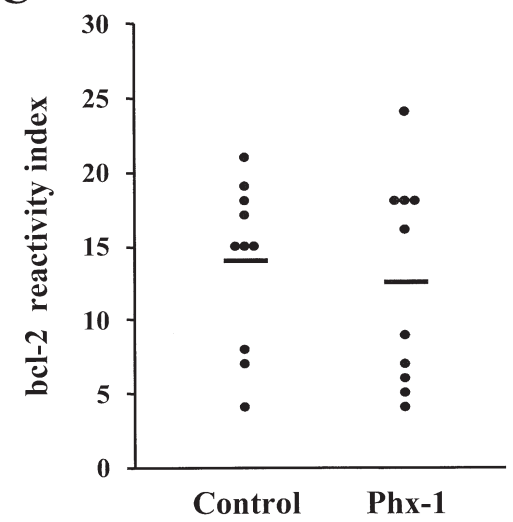

B

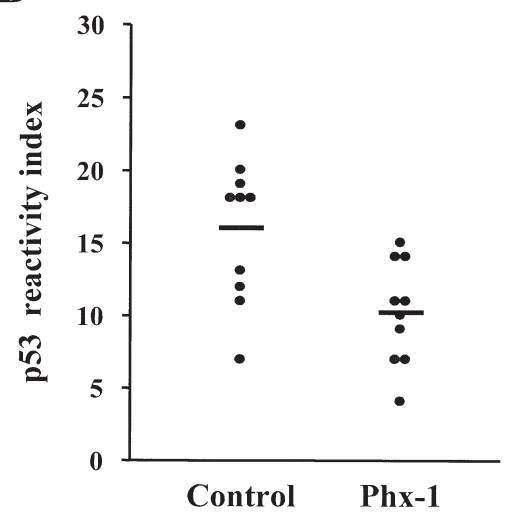

D

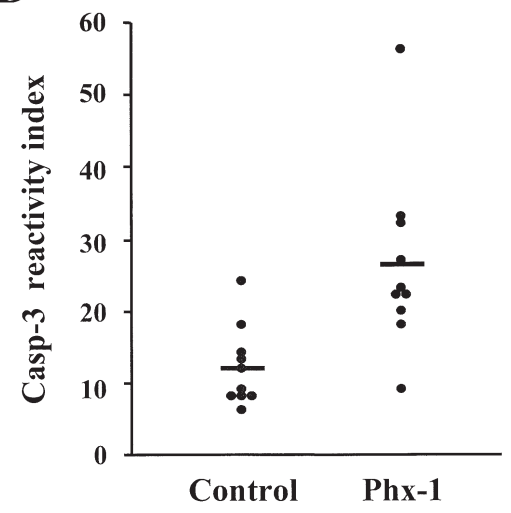

Figure 9. Effects of Phx-1 on Ki67, p53, bcl-2 and caspase-3 in a tumor mass of Y79 cells transplanted into nude mice, by using immunohistochemical staining. The data in the graphs were obtained from immunohistochemical staining results as shown in Fig. 8. Graphs show the number of tumor cells expressing Ki67, p53, bcl-2 and caspase-3 in each specimen of a tumor mass isolated from the mice transplanted with Y79 cells with Phx-1 (experimental group) or without Phx-1 (control group); bar in the figure is the mean value. (A) Ki67 reactivity index. The number of tumor cells expressing Ki67 was significantly higher in the control group (mean value 44.8, range 36-52) than in the Phx-1-treated group (mean value 28.6, range 19-47), p<0.05; (B) p53 reactivity index. The number of tumor cells expressing p53 was significantly lower in the Phx-1-treated group (mean value 10.2, range 4-15) than in the control group (mean value 15.9, range 7-23), p<0.05; (C) bcl-2 reactivity index. The mean value of tumor cell positive for bcl-2 in the control group was 13.9 (range 4-21) and that in Phx-1-treated group was 12.5 (range 4-24). There was no significant difference in bcl-2 positivity between the two groups ( $>0.05$ ). (D) Caspase-3 reactivity index. The number of tumor cells expressing caspase-3 was significantly higher in the Phx-1-treated specimen (mean value 26.2, range 9-56) than in the control group (mean value 12.0 , range $6-24), \mathrm{p}<0.05$.

malignant cell lines (9-11). $\mathrm{IC}_{50}$, the dose that caused $50 \%$ inhibition of cell growth was $\sim 50 \mu \mathrm{M}$ for Phx-1, when $\mathrm{Y} 79$ cells were treated with Phx-1 for 72 h (Fig. 2), being $~ 5$ times higher than those of 5-FU, respectively, because the concentrations which induce apoptosis of 5-FU against cultured cells such as the Chinese hamster ovary cell line, UV41 cells and AA8 cells were $\sim 10 \mu \mathrm{M}(17,18)$. In spite of this finding, Phx-1 suppressed the growth of Y79 cells transplanted into nude mice at lower concentrations $(5 \mathrm{mg}$ / $\mathrm{kg} / \mathrm{day})$, which was comparable to the dose of 5-FU (7.8 mg/ $\mathrm{kg} /$ day to mice) (9). Thus, the growth of the retinoblastoma Y79 cells was extensively suppressed in the nude mice when $5 \mathrm{mg} / \mathrm{kg} /$ day Phx-1 was injected and the size of the tumor decreased to almost half of the control without Phx-1, 35 days after the administration of Phx-1 (Figs. 4 and 5A-C). The reason why $\mathrm{Phx}-1$ exerts antitumor effects at different doses in vitro and in vivo as shown in Figs. 2, 4 and 5A-C, may be explained by the fact that $\mathrm{Phx}-1$ can be metabolized to some compounds that exert antitumor effects at lower concentrations in the body when administered to animals and that Phx-1 may exert antitumor effects in combination with cytokines, such as tumor necrosis factor-related apoptosis-inducing ligand (TRAIL). Hara et al (19) recently showed that Phx-1 augmented the inhibitory effects of TRAIL on the growth of Jurkat cells by $\sim 100$ times, in addition to the original antiproliferation effects of Phx-1 against these tumor cells, suggesting that Phx-1 may coordinate with some cytokines to kill tumor cells, when administered to the body.

It was demonstrated that $\mathrm{Phx}-1$ suppressed the proliferation of tumor cells by inducing apoptosis/necrosis in various cells (9-11). We found that Phx-1 induced mixed-type cellular death, i.e., apoptosis and necrosis, in Y79 cells (Fig. 3). Furthermore, we found that the tumor mass of Y79 cells transplanted into a nude mouse with $5 \mathrm{mg} / \mathrm{kg} /$ day $\mathrm{Phx}-1$, contained an increased number of degenerated cells with unclear nuclear structure (Fig. 7B) and with decreased mitotic figures (Figs. 7B and C), which may be attributed to the antiproliferative and apoptogenic activity of Phx-1 in vivo. A decreased Ki67 value in a mass of Y79 tumor of a mouse with Phx-1 (Fig. 9A) also suggested that the proliferation of the tumor was suppressed by $\mathrm{Phx}-1$, because Ki67 has been considered a good marker to evaluate the proliferation ability of cancers, especially of 
recurrent cancers (13). Caspase-3, bcl-2 and p53 are shown to be tightly associated with apoptosis in cancer cells in the presence of chemotherapeutic agents. The expression of the active form of caspase-3, which was detected by immunohistochemistry, was significantly increased (Fig. 8). This result is comparable to reports that apoptosis is associated with the activation of caspase-3 (15). Though we observed that the levels of p53 were decreased in the tumor of an experimental mouse (Fig. 9B), the interpretation of this behavior of p53 is ambiguous at present, because the mutated p53 could not be detected in human retinoblastoma cells (20) and therefore the wild-type p53 in the tumor could be measured in the present specimens and because Phx-1-induced down-regulation of the wild-type p53 seems to be resistant to chemotherapeutic treatment.

With regard to the levels of bcl-2, they were not altered in the tumor of an experimental mouse with $\mathrm{Phx}-1$ compared with those of a control mouse (Fig. 9C). It was shown that when Phx-1 was administered, the levels of bcl- 2 changed according to the cancer cells, i.e., the levels of bcl-2 were reduced in pancreatic cancer cells (21), while they were not altered in the multiple myeloma cell line U266 (our unpublished data). Therefore, the significance of changes in bcl-2 levels in cancer cells and cancer tissues affected by $\mathrm{Phx}-1$ remains unclear.

It was recognized that the induction of apoptosis of tumor cells may be benevolent, because it did not cause inflammation of the tissues nearby and did not cause adverse effects. Thus, we studied the adverse effects of Phx-1 on nude mice. We found that $5 \mathrm{mg} / \mathrm{kg} /$ day $\mathrm{Phx}-1$ did not cause change in body weight even 35 days after its administration (Fig. 6) and that 40 $\mathrm{mg} / \mathrm{kg}$ /day $\mathrm{Phx}-1$, which was administered as a suspension of the compound in ethanol solution, did not cause special adverse effects including loss of bodyweight (data not shown), being consistent with the results of Mori et al (9) and Shimamoto et al (10) that Phx-1 did not cause bodyweight loss or bone marrow suppression in mice. Phx-1 can be expected to be available for therapeutic purposes of retinoblastoma in the future, because Phx-1 shows strong antitumor activity on Y79 cells transplanted into mice, without any adverse effects.

\section{Acknowledgements}

We are grateful to Professor J. Patrick Barron, The International Medical Communications Center, Tokyo Medical University for reviewing the present manuscript. We are also grateful to Koji Fujita, Department of Pathology, Tokyo Medical University for technical assistance of histopathology. This study was supported by a grant from the High-Tech Research Project for Private Universities with a matching fund subsidy from the Ministry of Education, Culture, Sports, Science and Technology, Japan (2003-2007).

\section{References}

1. Shields JA and Shields CL: Current management of retinoblastoma. Mayo Clin Proc 69: 50-56, 1994.

2. Bishop JO and Madsen EC: Retinoblastoma; review of the current status. Surv Ophthalmol 19: 342-366, 1975.

3. Yanagisawa T: Systemic chemotherapy as a new conservative treatment for intraocular retinoblastoma. Int J Clin Oncol 9: 13-24, 2004.
4. Rodriguez-Galindo C, Wilson MW, Haik BG, Merchant TE, Billups CA, Shaha N, Cain A, Langston J, Lipson M, Kun LE and Pratt CB: Treatment of intraocular retinoblastoma with vincristine and carboplatin. J Clin Oncol 21: 2019-2025, 2003.

5. Meadows AT, Baum E, Fossanti BF, Green D, Jenkin RDT, Marsden B, Nesbit M, Newton W, Oberlin O, Sallan SG, Siegel S, Strong LC and Voute PA: Second malignant neoplasms in children: an update from the late effects study group. J Clin Oncol 3: 532-538, 1985.

6. Tomoda A, Hamashima H, Arisawa M, Kikuchi T, Tezuka Y and Koshimura S: Phenoxazine synthesis by human hemoglobin. Biochem Biophys Acta 1117: 306-314, 1992.

7. Tomoda A, Arai S, Ishida R, Shimamoto T and Ohyashiki K: An improved method for the rapid preparation of a novel antitumor agent. Bioorg Med Chem Lett 11: 1057-1058, 2002.

8. Hollstein U: Actinomycin. Chemistry and mechanism of action. Chem Rev 74: 625-652, 1974.

9. Mori H, Honda K, Ishida R, Nohira T and Tomoda A: Antitumor activity of 2 -amino-4,4 $\alpha$-dihydro- $4 \alpha, 7$-dimethyl- $3 \mathrm{H}$ phenoxazine-3-one against Meth A tumor transplanted into BALB/c mice. Anticancer Drugs 11: 653-657, 2000.

10. Shimamoto T, Tomoda A, Ishida R and Ohyashiki K: Antitumor effect of a novel derivative on human leukemia cell lines in vivo and in vitro. Clin Cancer Res 7: 704-708, 2001.

11. Koshibu-Koizumi J, Akazawa M, Iwamoto T, Takasaki M, Mizuno F, Kobayashi R, Abe A and Tomoda A: Antitumor activity of a phenoxazine compound, 2 -amino- $4,4 \alpha$-dihydro4 $\alpha, 7$-dimethyl-3H-phenoxazine-3-one against human B cell and $\mathrm{T}$ cell lymphoblastoid cell lines: induction of mixed types of cell death apoptosis and necrosis. J Cancer Res Clin Oncol 128: 363-368, 2002.

12. Miyano-Kurosaki N, Kurokaski K, Hayashi M, Takaku H, Hayafune M, Shirato K, Kasuga T, Endo T and Tomoda A: 2-Aminophenoxazine-3-one suppresses the growth of mouse malignant melanoma B16 cells transplanted into C57BL/6Cr Slc mice. Biol Pharm Bull 29: 2197-2201, 2006.

13. Healy E, Angus B, Lawrence CM and Rees JL: Prognostic value of Ki67 antigen expression in basal cell carcinomas. Br J Dermatol 133: 737-741, 1995.

14. Vidal D: Efficacy of imiquimod for the expression of Bcl-2, Ki67, p53 and basal cell carcinoma apoptosis. Br J Derm 151: 656-662, 2004.

15. Lustosa SA, Logullo A, Artigiani R, Saad SS, Goldenberg A and Matos D: Analysis of the correlation between p53 and bcl-2 expression with staging and prognosis of the colorectal adenocarcinoma. Acta Cir Bras 20: 353-357, 2005.

16. Green D and Kroemer G: The central executioners of apoptosis: caspases or mitochondria? Trends Cell Biol 8: 267-271, 1998.

17. Barry MA, Behnke CA and Eastman A: Activation of programmed cell death (apoptosis) by cisplatin, other anticancer drugs, toxins and hyperthermia. Biochem Pharmacol 40: 2353-2362, 1990.

18. Kung AL, Zetterberg A, Sherwood SW and Schimke RT: Cytotoxic effects of cell cycle phase-specific agents: a result of cell cycle perturbation. Cancer Res 50: 7307-7317, 1990.

19. Hara K, Okamoto M, Aki T, Yagita H, Tanaka H, Mizukami Y, Nakamura H, Tomoda A, Hamasaki N and Kang D: Synergistic enhancement of TRAIL- and TNF $\alpha$-induced cell death by a phenoxazine derivative. Mol Cancer Ther 4: 1121-1127, 2005.

20. Schlamp CL, Poulsen GL, Nork TM and Nickells RW: Nuclear exclusion of wild-type p53 in immortalized human retinoblastoma cells. J Natl Cancer Inst 89: 1533-1536, 1997.

21. Kato S, Shirato K, Imaizumi K, Toyota H, Mizuguchi J, Odawara M, Che XF, Akiyama S, Abe A and Tomoda A: Anticancer effects of phenoxazine derivatives combined with tumor necrosis factor-related apoptosis-inducing ligand on pancreatic cancer cell lines, KLM-1 and MIA-PaCa-2. Oncol Rep 15: 843-848, 2006. 